\title{
¿La Apoteosis de Heracles o una escena de Apobates? A propósito de una cratera de campana procedente de La Loma del Escorial de Los Nietos (Cartagena, Murcia)*
}

\section{The Apotheosis of Heracles or the Apobates race? Revisiting a bell crater from La Loma del Escorial de Los Nietos (Cartagena, Murcia)}

\author{
Diana Rodríguez Pérez \\ Beazly Archive. Universidad de Oxford
}

\section{RESUMEN}

En el presente artículo se revisa la identificación iconográfica de la cara A de una cratera griega fragmentaria del siglo IV a.C. procedente del yacimiento ibérico de La Loma del Escorial de Los Nietos (Cartagena, Murcia). La escena se ha identificado tradicionalmente como la apoteosis de Heracles, no obstante, tras un análisis detallado de la misma, en particular del resto de un escudo previamente inadvertido que porta el personaje principal, creemos que la iconografía se corresponde con la del apobates victorioso, un unicum en la Península Ibérica. Presentamos un análisis de ambos motivos iconográficos que revelará interesantes conclusiones sobre el funcionamiento de los tipos iconográficos y mecanismos de creación de significado en la pintura de vasos de la época, así como sobre el tipo de imágenes estimadas por los receptores de esas piezas en la Península Ibérica, los íberos. Se incluye también un catálogo actualizado de los vasos áticos que portan ambos temas.

\section{SUMMARY}

The aim of this article is to assess the traditional iconographic identification of the obverse of a $4^{\text {th }}$ century Greek bell crater from the Iberian site of La Loma del Escorial de Los Nietos (Cartagena, Murcia). The scene has been identified as an apotheosis of Heracles. Nevertheless, a detailed analysis of its iconography and of a feature neglected in the previous study of the vase by its excavators - the remains of a shield - make it possible to argue in favor of an apobates race instead - the only scene of this type attested in the Iberian Peninsula. I present here an analysis of both iconographic motifs - the apotheosis

\footnotetext{
* Esta investigación está financiada por un contrato postdoctoral del Ministerio de Educación, Cultura y Deporte disfrutado en la Universidad de Edimburgo (2012-2014). Agradezco a Miguel Martín Camino, del Museo Arqueológico Municipal de Cartagena, su amabilidad al facilitarme las fotografías de la cratera objeto de este estudio, así como a los revisores anónimos de esta revista por sus sugerencias. Cualquier error es responsabilidad mía.
}

of Heracles and the apobates race- that will reveal interesting findings on the ways in which images and iconographic types acquire meaning. It also sheds light on the kind of images favored by the receptors of these vases in the Peninsula - the Iberians. An up-to-date catalogue of Attic vases depicting each theme is included.

PALABRAS CLAVES: iconografía, vasos griegos, figuras rojas, nice, partenón, cratera de campana.

KEY WORDS: iconography, Greek Vase Painting, Red-Figure Vases, Nike, Parthenon, bell crater.

Se presenta en estas líneas una revisión sobre una cratera griega fragmentaria procedente del yacimiento ibérico de La Loma del Escorial de Los Nietos (Cartagena, Murcia) y dada a conocer en esta misma revista por Carlos y José Miguel García Cano en 1992 (García Cano y García Cano 1992) (Figs. 1 y 2). El propósito de este artículo es revisar la identificación iconográfica de la pieza y situarla en el contexto más amplio de la producción griega de cerámica figurada en los últimos decenios del siglo $\mathrm{v}$ y el primer cuarto del siglo IV a.C. Asimismo, el análisis de dos motivos iconográficos muy cercanos - la apoteosis de Heracles y la carrera de apobates - revelará interesantes conclusiones sobre el funcionamiento de los tipos iconográficos y los mecanismos de creación de significado en la pintura de vasos de la época. Se incluye además un catálogo actualizado de los vasos áticos que portan ambos temas ${ }^{1}$.

\footnotetext{
${ }^{1}$ Las referencias en el texto al catálogo se proporcionan entre paréntesis. "H" se refiere a las imágenes de la apoteosis
} 


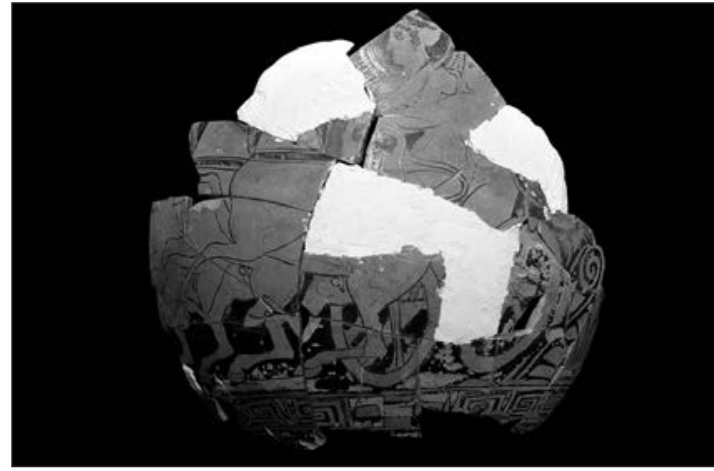

Figura 1. Cratera de campana número 6 de Los Nietos. Fotografía: () Museo Arqueológico Municipal de Cartagena.

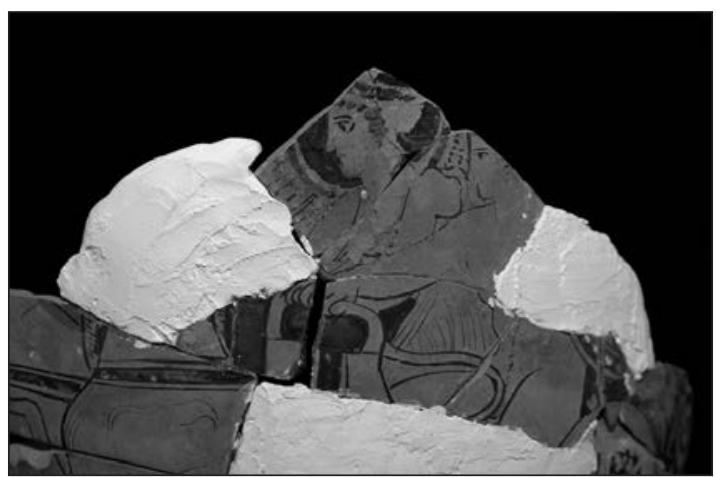

Figura 2. Detalle de la cratera de campana número 6 de Los Nietos. Fotografía: (c) Museo Arqueológico Municipal de Cartagena.

Esta pieza forma parte de un importante lote de crateras de campana áticas halladas en una habitación del poblado ibérico de La Loma del Escorial, un conjunto muy remarcable tanto para el estudio de las producciones figuradas griegas en esta época como para el análisis del comercio de dichas producciones con la Península Ibérica. Algunas de ellas han sido recientemente reatribuidas por J. M. García Cano y Francisco Gil (García Cano y Gil 2009) a destacados pintores de la primeras décadas del siglo IV a.C., tales como el pintor de Enomao, y puestas en relación con otras importantes crateras de campana griegas halladas en la Península Ibérica, en particular, con la Tumba 43 de Baza (sobre esta tumba, Sánchez Fernández 1997).

La cratera objeto de este estudio es la número 6 del catálogo de C. y J. M. García Cano (García Cano

de Heracles y "AP”, a las de apobates. La abreviatura BADN se refiere al "Beazley Archive Database Number", que se puede consultar en http://www.beazley.ox.ac.uk/index.htm. La abreviatura LIMC se refiere al "Lexikon Iconographicum Mythologiae Classicae". y García Cano 1992: 24), datada por ellos en el segundo cuarto del siglo IV a.C. Incluyen los autores esta pieza dentro de las referentes al "Ciclo de Hércules"e identifican la escena como "Hércules conducido al Olimpo en una cuadriga por una Nike". Un punto en particular de la descripción iconográfica de la pieza llamó nuestra atención: tras describir las figuras, afirman que "por detrás asoman varias ovas del friso que remata el arranque de las asas" y, más adelante, "[...] Hércules, mostrado como un joven imberbe, que debe llevar la clava en su mano izquierda, apoyada en el antebrazo, tal y como suele representarse en otros vasos de este periodo con el mismo tema" (García Cano y García Cano 1992: 24). Esta sería la única ocasión en la que aparecería esta iconografía en la Península Ibérica. No obstante, hay un detalle iconográfico que los autores han pasado por alto: la presencia de un resto de lo que parece a todas luces un escudo junto a las ovas que los autores identifican detrás de las figuras o que quizá confunden con las propias ovas que rematarían el asa.

Ya que la presencia del escudo es el argumento principal para revisar la actual identificación iconográfica de la escena, es necesario justificar esta identificación mediante la comparación con escudos completos en vasos contemporáneos. El resto de escudo de la cratera de Los Nietos corresponde a un tipo que aparece en otras ocasiones en la pintura de vasos contemporánea y cuyo mejor paralelo — con ligeras diferencias - lo ofrecen los que se figuran en otra de las crateras del conjunto de Los Nietos, la número 3, así como en la cratera de Baza 43A — esta sin la línea negra sólida rodeando el diámetro exterior-, o en una cratera de campana de la colección Durand en el Museo del Louvre con una escena de apobates (AP14) (Fig. 3). Estos escudos presentan como episema el sol de Vergina acompañado de un punteado blanco externo que enmarca su diámetro. En nuestra imagen solo se conserva un pequeño fragmento del mismo pero creemos que es fácil reconstruir el resto en esta zona en base a lo conservado. El escudo podría aparecer originariamente completo o verse interrumpido por el arranque del asa, tal y como aparece en la cratera mencionada de la colección Durand. Esta ofrece el mejor paralelo de lo que pudo ser la escena de Los Nietos. Aquí, la cuadriga al galope es conducida por Nice y ocupa toda la superficie de la cara A. El apobates está tocado con un yelmo emplumado - la cratera de Los Nietos está estratégicamente rota en el punto en el que moriría la parte inferior del casco aunque se adivinan restos de la cinta blanca alrededor del cuello - y el escudo que porta en la mano izquierda se interrumpe por la presencia de las ovas que rodean el arranque del asa. 


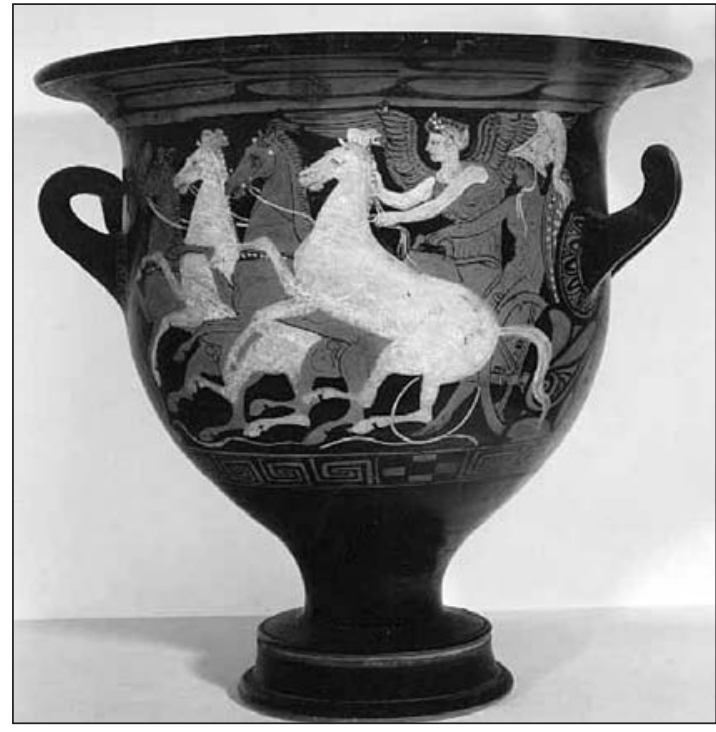

Figura 3. Cratera de campana de figuras rojas con la representación de un carro con auriga (Nice) y apobates. París, Museo del Louvre G527, colección Durand. Fotografía: Metzger 1951: Pl.48.41.

Así pues, si la representación de un escudo en esta parte es, en nuestra opinión, plausible, creemos que es necesario refutar la identificación tradicional de la escena como la apoteosis de Heracles y proponer en cambio una escena de apobates, un caso igualmente único en la Península Ibérica. Ambos tipos de representaciones fueron bastante comunes en la cultura visual ática de la época y la iconografía de ambas va mimetizándose según avanza el siglo v y en especial durante el IV a.C., cuando se producen interesantes concomitancias entre ellas. En su formulación más básica, el único elemento definitivo para diferenciar ambas escenas será, precisamente, el escudo.

En las líneas siguientes vamos a realizar un estudio de ambos temas, definiremos sus motivos iconográficos y compositivos básicos en los siglos $\mathrm{v}$ y IV a. C., y analizaremos las interesantes relaciones que se establecen entre ellas en esta época así como las implicaciones de las mismas en relación con el significado último que adquieren estas imágenes en contexto ibérico.

\section{LA APOTEOSIS DE HERACLES}

En una obra muy temprana, Mingazinni dividió las escenas de la apoteosis del héroe en catorce tipos principales (Mingazzini 1925: 419). Cuatro de ellos se refieren a las representaciones de la cuadriga de Heracles, con distintas variaciones: las versiones clá- sicas que muestran el carro volando por el espacio o corriendo al galope y el esquema arcaico de cuadriga parada en el que el héroe se acompaña de Atenea o de Iolao. El resto de grupos incluyen las escenas de apoteosis sin carro, es decir, la introducción de Heracles en el Olimpo a pie, el reposo y banquete en el Olimpo, el héroe como parte del tiasos báquico, recibiendo una corona triunfal, etc.

Las imágenes más antiguas del tipo son las conocidas escenas de la introducción del héroe en el Olimpo en las que se representa la cuadriga estática $\mathrm{y}$ al héroe junto Atenea o Iolao. Estas imágenes, frecuentes en los vasos de figuras negras de la segunda mitad del siglo vi a.C. (Shapiro 1990: 125-126), son bastante conocidas a raíz de la publicación de una serie de artículos pioneros en los años setenta, en los que Boardman interpretaba el aumento de las escenas de Heracles en esta época a la luz de un posible simbolismo político como resultado de la apropiación iconográfica del héroe por parte de Pisístrato, y las escenas de la cuadriga en particular, como propaganda pisistrátida alusiva al retorno del tirano a Atenas (Boardman 1972, 1975, 1989b). En estas imágenes la cuadriga aparece estática y mira hacia la derecha.

No obstante, las representaciones que nos interesan aquí son las que muestran el carro del héroe avanzando, tanto por el suelo como surcando el cielo, hacia el Olimpo, con mención expresa a la pira en la que el héroe se inmola. Este es un desarrollo iconográfico tardío que se registra en la pintura de vasos, tanto ática como suditálica, en torno al año 420 a.C.

El desarrollo más completo del tema, Heracles en la cuadriga volando sobre la pira, se encuentra en tres vasos áticos de finales del siglo v y principios del IV: una pélice de figuras rojas del pintor de Cadmo procedente de Vulci (420-400) (H3) (Fig. 4), una cratera de cáliz de figuras rojas en Nueva York no atribuida pero que se puede relacionar con el entorno del pintor de Londres F64 (H1) (Fig. 5), y una cratera de campana de figuras rojas del pintor de Londres F64 procedente de Sant'Agata de' Goti (H2). Además de estas tres piezas áticas, hay dos crateras apulias que recogen el mismo tema (Vollkommer 1988: 36) y un número de fialas que se decoran en el interior con un friso de carros al galope tirados por Nice, entre ellos, el de Heracles —el héroe asciende al Olimpo acompañado de un amplio cortejo de divinidades(Richter 1941).

Las tres composiciones son bastante elaboradas, con figuras en distintos planos y bastante movimiento, en particular, la de Nueva York. La composición de las tres se divide en dos registros, uno superior en el que vuela la cuadriga siempre hacia la izquierda y uno inferior dedicado a la pira de Heracles. En el 


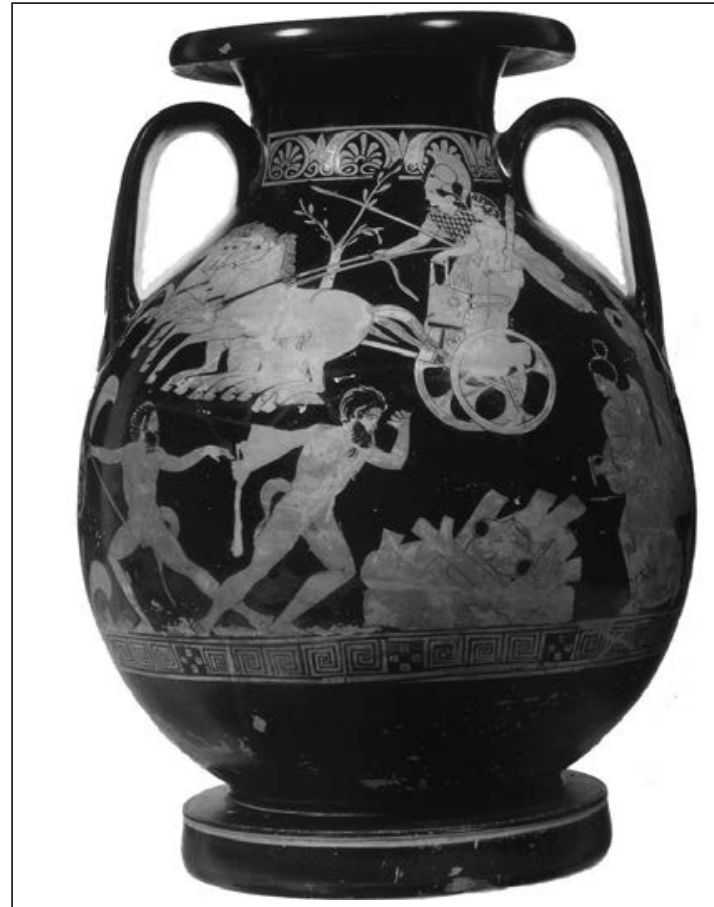

Figura 4. Pélice de figuras rojas con la representación de la apoteosis de Heracles. München, Antikensammlung 2630. Fotografía: Brinkmann et alii 2003: 282 .

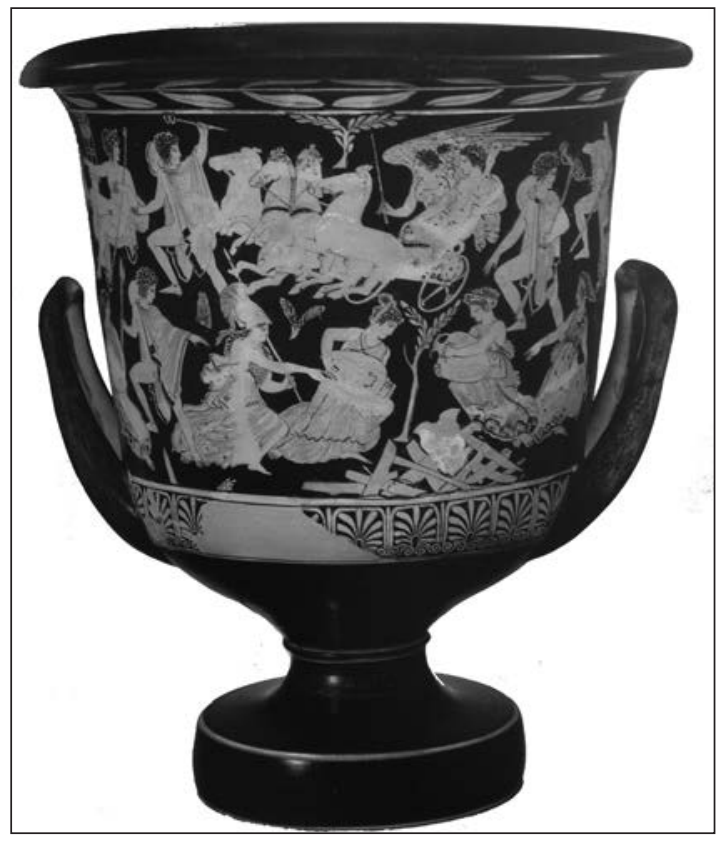

Figura 5. Cratera de cáliz de figuras rojas con la representación de la apoteosis de Heracles. Nueva York 52.11.18. Fotografía: Mertens 2010: 152. vaso del pintor de Cadmo, el más temprano, Atenea conduce el carro, acompañada del héroe, estante sobre el mismo y portando la clava y el manto enrollado en el brazo izquierdo. En las otras dos piezas es Nice quien conduce la cuadriga. Cuatro caballos encabritados sirven de tiro. En el registro inferior arde la pira funeraria en la que se representa la armadura del héroe como único resto físico de él en la tierra. A esta pira se acercan dos mujeres con hidrias llenas de agua mientras dos sátiros (Skopas y Hybris) gesticulan en el lado opuesto (a ellos volveremos luego). La referencia nupcial entra en escena mediante el gesto de la novia que realiza una de las hidroforas ${ }^{2}$. Esta pélice del pintor de Cadmo parea la escena de la apoteosis con sátiros y ménades en el reverso; la cratera de Nueva York, con una Amímone rodeada de sátiros; y la del Pintor de Londres F64, con una típica escena de jóvenes en la palestra.

Las dos crateras de principios del siglo IV introducen un personaje nuevo en la escena: Hermes, en su papel de dios de los caminos del más allá. Este personaje será especialmente querido por el pintor de Londres F64, que lo incluye aún en las versiones más simplificadas de la escena. Este pintor es uno de los principales representantes del Plainer Group de Beazley y recurre a este tema en múltiples ocasiones para decorar sus crateras de campana. Su versión desarrollada del mito aparece en el vaso de Sant'Agata de' Goti en el que, además de Hermes, introduce a Apolo sosteniendo la eirisione, un dios que a partir de este momento aparece íntimamente ligado con Heracles y también con Dioniso.

A partir de ahora el tema se va simplificando y solo se incluyen los elementos significativos mínimos necesarios para la comprensión del tema, el núcleo de la narración: Heracles —identificado por la clavaacompañado de Nice en una cuadriga que avanza hacia la izquierda. El héroe adopta, en ocasiones, un gesto característico del apobates sobre el que volveremos luego: el del desmonte del carro. Ocasionalmente, aparece Hermes como guía (Fig. 6).

${ }^{2}$ El viaje de Heracles al Olimpo es también un viaje erótico, el viaje hacia su boda con Hebe, como se explicitará más adelante en una cratera del pintor del Louvre G508 que figura a la joven Hebe repitiendo el mismo gesto (anakálipsis) junto a un Heracles victorioso representado dentro de una particular estructura utilizada en la iconografía exclusivamente en relación con él. Sobre esta estructura, véase Frickenhaus 1911 y Woodford 1971: 213. 


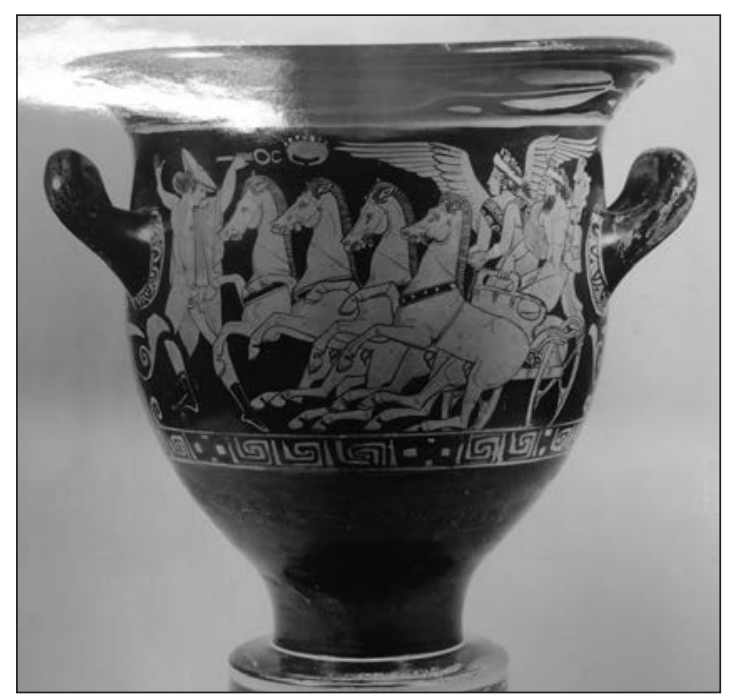

Figura 6. Cratera de campana de figuras rojas con la representación de la apoteosis de Heracles. Ruvo, Museo Jatta 422. Fotografía: Boardman 1989a: Fig.354.

\subsection{ORIGEN DEL TEMA Y RELACIONES}

Las imágenes de la introducción del héroe en el Olimpo fueron populares desde el arcaísmo pero la unión de la pira funeraria con el carro no se produce en la pintura de vasos hasta finales del siglo v a.C. Shapiro ha explicado la curiosa muerte del héroe en forma de inmolación deliberada como un curioso instrumento destinado a ser compatible con la idea de la apoteosis, una ingeniosa solución para presentar la difícil transición de hombre a dios (1983: 10, 15). Aunque la primera narración más o menos continua del suceso la encontramos en las Tarquinias de Sófocles, los diversos elementos del mito eran conocidos ya desde antiguo. Existen testimonios de un festival del fuego celebrado al menos desde el siglo vi a.C. en el Monte Eta y vinculado con el mito de Heracles por Nilsson (1963: 205). Contamos también con un número de referencias oscuras a la muerte del héroe por el fuego antes de esta tragedia (Cochrane 1991: 59). No obstante, en las Tarquinias, cuya cronología es debatida — se proponen fechas desde 450 hasta el 420 a.C.- , no se hace mención expresa a la apoteosis del héroe, ausencia que ha generado una abundante bibliografía ${ }^{3}$.

Antes del año 450 a.C. existen tres representaciones de la pira de Heracles sin referencia al carro

${ }^{3}$ El debate sobre el final de las Tarquinias se ha centrado en dirimir si Sófocles - y su audiencia - conocían la versión de la apoteosis del héroe tras su muerte en la pira y, en caso afirmativo, por qué (o si en realidad) este aspecto no se alude en la obra (Holt 1989; Cochrane 1991; Finkelberg 1996).
(Clairmont 1953: 85-90; Holt 1989: 73; Faraone 1997: 44), pero será, como avanzamos antes, alrededor del año 420 a.C. cuando pira y apoteosis se unan en las artes visuales.

\subsubsection{El drama satírico}

La presencia de sátiros en estas imágenes ha dado pie a diversos investigadores a proponer que estas piezas están reproduciendo una representación de un drama satírico ático perdido ${ }^{4}$, en concreto de la obra de Sófocles, Heracles Satyricus (Sutton citada por Faraone 1997: 44). No obstante, este tema es controvertido. Los pintores de vasos, interesados en numerosos aspectos de la vida cotidiana y mitológica de su país, pudieron haber representado en ocasiones puntuales episodios concretos de obras literarias o representaciones teatrales de las mismas en sus obras pero, con excepción de ciertas piezas muy particulares y conocidas, tales como el vaso de Prónomos (Taplin y Wyles 2010), es muy complicado identificar escenas particulares como ilustraciones de obras teatrales (entre los estudios pioneros sobre el tema, destacan el de Brommer 1944 y el de Trendall y Webster 1971).

Estos casos suelen reconocerse por una serie de signos iconográficos, tales como el entorno arquitectónico, que recuerda a la escena del teatro (pórticos), las ropas, la máscara, las botas (kothornos, en particular en relación con la tragedia), el arco de rocas, los trípodes o las inscripciones o dipinti en dialecto ático, entre otras (Taplin 2007: 35-43). No obstante, muchos de estos signos, como recuerda Taplin (2007: 37), se habían introducido ya, en particular en el siglo IV a.C., en iconografías que nada tienen que ver con temas teatrales. Sobre este asunto se pronuncia también Mitchell en su reciente trabajo sobre el humor visual en los vasos griegos y considera que los sátiros en este tipo de obras no se deben entender como referentes a supuestos dramas satíricos perdidos sino como figuras cómicas de pleno derecho; es decir: no son actores interpretando a sátiros, sino sátiros comportándose como tales. Así, Mitchell, muy crítico con Sutton, solo admite la hipótesis de la influencia literaria cuando hay signos claros que aludan a ella, en particular, la vestimenta (2009: 150-235). Los sátiros son presencias muy comunes en la pintura mitológica y su mera presencia no prueba la existencia de

\footnotetext{
${ }^{4}$ Sobre el drama satírico, véase Seidensticker 1989. Una lista con dramas satíricos cuya existencia está documentada, es probable o debe ser refutada puede encontrarse en Sutton 1974 y se incluye también en el volumen mencionado editado por Seidenstricker.
} 
un drama satírico perdido contemporáneo ${ }^{5}$. François Lissarrague ha insistido particularmente en este tema y ha demostrado que existen otras muchas razones, culturales e iconográficas, que explican la aparición de sátiros en la iconografía, sin acudir al argumento del drama satírico (1990).

No obstante, si bien consideramos que no estamos tratando con ilustraciones específicas de comedias o dramas satíricos perdidos, creemos posible que una producción literaria de ese tipo pudiera haber inspirado temáticamente a los pintores de vasos contemporáneos $^{6}$. Otra posibilidad es que tanto los pintores de vasos como los literatos estuvieran respondiendo a un interés creciente en el episodio de la apoteosis de Heracles como respuesta a otros factores, quizá de índole religiosa, sobre los que no tenemos conocimiento (sobre los cultos del héroe en el Ática, véase Woodford 1971). Contamos, no obstante, con algunos indicios que podrían apoyar la teoría de la influencia de una obra literaria en el caso que estamos tratando. Una enócoe ática del pintor de Nicias hoy en el Museo del Louvre (H14) y datada sobre el año 410 a.C. muestra una versión de la apoteosis de Heracles indudablemente cómica: los personajes de Heracles y de Nice presentan todos los rasgos que aluden de manera clara a las máscaras cómicas mientras que el personaje que abre camino con dos antorchas en una suerte de Hermes cómico porta el equipamiento completo, incluido el largo falo artificial. Taplin remarca que esta escena es "far from playable" pero que está indudablemente imbuida de una "atmosphere of fantastical comedy" (1993: 9-10). Esta pieza, contemporánea a nuestras producciones, demostraría, por lo tanto, la existencia de una interpretación en clave cómica de la apoteosis del héroe con un origen presumiblemente teatral a finales del siglo v a.C. No obstante, este vaso procede de la Cirenaica, lo que reduce considerablemente su valor como testimonio de las realidades atenienses contemporáneas. La cratera de campana del Metropolitan parea la apoteosis con una escena de Amímone que podría también presentar relaciones con un drama satírico. Los pintores de vasos comienzan a representar la saga de Amímone y

\footnotetext{
${ }^{5}$ Holt interpreta que los sátiros están, de hecho, robando el armamento de Heracles de la pira, una idea muy interesante que trae a la mente una cratera de campana apulia en la que dos sátiros roban el armamento a Heracles mientras este sujeta el mundo en relevo de Atlas (Mitchell 2009: 152, fig.171).

${ }^{6}$ La visión de Taplin al respecto, intermedia entre el iconocentrismo de Lissarrague y el literalismo de Sutton, nos parece la más acertada. En este sentido, considera, por ejemplo, que la existencia de más de una docena de vasos áticos en los que se figura a Prometeo ofreciendo fuego a los sátiros indica que es muy probable que dichas imágenes se inspiraran en el drama satírico de Esquilo correspondiente (Taplin 2007: 34).
}

los sátiros alrededor del año 440 a.C. y Brommer, a propósito de una cratera de campana de Viena de la mano del Pintor del Dinos (Kunsthistorisches Museum 1011; BADN 215306) que porta una composición muy similar al reverso del vaso de Nueva York, relaciona estas escenas "sin lugar a dudas" con un drama satírico (Brommer (1944: 21-23) refiere la existencia de un drama satírico de Esquilo titulado Amímone, también documentado por Sutton (1974: 123).

Finalmente, otro detalle iconográfico de la cratera de Nueva York es interesante en cuanto a la posible relación de estas piezas con una obra teatral. Se trata del trípode que cierra la composición por la izquierda, en la zona del asa. Los trípodes de bronce constituían un trofeo prestigioso y fueron objeto de dedicatorias desde muy antiguo. Están asociados con la victoria y aparecen en dos ocasiones en el vaso de Prónomos. Los trípodes no se representan con asiduidad en la pintura de vasos, aunque aparecen en escenas asociadas con Delfos, pero también, significativamente, en una serie de vasos relacionados con el teatro, por lo que es plausible su significado como referentes a la victoria en la competición (Taplin 2007: 43). En otras ocasiones, no obstante, la falta de otros indicios en la escena hace necesario interpretar el trípode en otro sentido, no como un signo alusivo a la victoria en una competición literaria de la obra teatral representada, sino más bien como un signo de victoria alusivo al personaje principal de la composición. Tal interpretación es plausible, por ejemplo, en el caso de un vaso del pintor de Nicias con una escena de Heracles victorioso acompañado de Atenea, Nice y dos jóvenes (Londres, Museo Británico E498).

Así pues, tanto los testimonios iconográficos como los literarios apuntan a un interés creciente del tema de la apoteosis de Heracles y, en particular, de la inmolación en la pira, durante los últimos decenios del siglo v a.C. Las primeras plasmaciones iconográficas del tema denuncian una influencia literaria, sin ser, probablemente, representaciones de dramas satíricos concretos y acuñan una iconografía característica que, simplificada, se repetirá en las siguientes imágenes del tema y que dejará sentir su influencia en las representaciones de los carros victoriosos de la carrera de apobates, como veremos a continuación.

\subsection{Apoteosis de Heracles en carro (vasos Áti- cos). Catálogo}

Heracles en la cuadriga sobre la pira:

1. Nueva York 52.11.18. Cratera de cáliz de figuras rojas. 400-380 a.C. La atribuimos al círculo 
del pintor de Londres F64. BADN 14714; LIMC Herakles 2917. (Mertens 2010: 152).

2. Sant'Agata de' Goti, Colección Mustili. Cratera de campana de figuras rojas. 400-380 a.C. Pintor de Londres F64. De Sant'Agata de' Goti, Italia. BADN 260021. (Vollkommer 1988: 45).

3. München, Antikensammlung 2630. Manera del Pintor de Cadmo. De Vulci, Etruria. 420 a.C. BADN 215719; LIMC Herakles 2916. (Brinkmann et alii 2003: 282).

Heracles en la cuadriga, sin pira, y acompañado por Nice o Atenea:

Pintor de Londres F64

4. Paris, Cabinet des Medailles 430. Cratera de cáliz de figuras rojas. Pintor de Londres F64. 400-380 a.C. BADN 260019.

5. Londres, British Museum F64. Cratera de cáliz de figuras rojas. Pintor de Londres F64. BADN 260017; LIMC Herakles 2922.

6. Oxford, Ashmolean Museum 1954.263. Fragmento. Figuras rojas. Pintor de Londres F64. BADN 260018.

7. Ruvo, Museo Jatta 422. Cratera de campana de figuras rojas. Pintor de Londres F64. 400-380 a.C. De Ruvo, Apulia. BADN 260020; LIMC Hermes 463B.

Pintor de Upsala

8. Bologna, Museo Civico Archeologico 318. Cratera de campana de figuras rojas. Pintor de Upsala. 400-380 a.C. BADN 218063.

9. Oxford, Colección Mynors, St. Weonards. Cratera de cáliz de figuras rojas. 400-380 a.C. Pintor de Upsala. BADN 218072; LIMC Herakles 2924.

\section{Grupo de Ferrara T 376 B}

10. Ferrara, Museo Nacional de Spina T376 BVP. Cratera de campana de figuras rojas del Grupo de Ferrara T376 B. 400-380 a.C. BADN 260058; LIMC Herakles 2923.

11. Ferrara, Museo Nacional de Spina T376 BVPA. Cratera de campana de figuras rojas del Grupo de Ferrara T476 B. 400-380 a.C. BADN 260059.

12. Ferrara, Museo Nacional de Spina T376 BVPB. Cratera de campana de figuras rojas del Grupo de Ferrara T476 B. 400-380 a.C. BADN 260060.
Otros

13. Viena, Kunsthistorisches Museum 933. Cratera de campana de figuras rojas. 400-380 a.C. Grupo de Budapest. BADN 218091.

14. París, Museo del Louvre N3408. Enócoe de figuras rojas. Pintor de Nicias. Fines del v a.C. BADN 217495; LIMC Herakles 1429. (Boardman 1989a: il. 321, Taplin 1993: 9-10, Walsh 2009: 236-237).

15. Birmingham, City Museum 1620.85. Cratera de cáliz de figuras rojas.

\section{Fragmentos}

16. Ágora P15594. Fragmento de una cratera de campana de figuras rojas. Cercano al pintor de Londres F64 y de la misma mano que Pnyx P171 y Ágora P22624. Primer cuarto del siglo IV a.C. (Moore 1997: n. 440, pl. 452).

17. Ágora P22624. Fragmento de una cratera de campana de figuras rojas. Cercana al Pintor de Londres F64 y de la misma mano que Ágora P15594 y Pnyx P171. Primer cuarto del siglo IV a.C. (Moore 1997: n.441, pl. 452).

18. Ágora P3035. Fragmento de una cratera de campana de figuras rojas (identificación dudosa). Cercana al Pintor de Londres F64. Primer cuarto del siglo IV a.C. (Moore 1997: n.442, pl. 452).

19. Ágora P4933. Fragmento de una cratera de campana de figuras rojas (identificación dudosa, Nice). Primer cuarto del siglo IV a.C. (Moore 1997: n.475, pl. 454).

20. Ágora P8734. Fragmento de un plato de figuras rojas. Primer cuarto del siglo IV a.C. (Moore 1997: n.1192, pl. 1112).

21. Pnyx P 171. Fragmento de una cratera de campana de figuras rojas. Cercana al Pintor de Londres F64 y de la misma mano que Ágora 440 y Ágora 441. Primer cuarto del siglo IV a.C. (Talcott y Philippaki 1956: 57, n. 255, pl. 224).

22. Pnyx P 226. Fragmento de una cratera de campana de figuras rojas. Pintor de Londres F64. Primer cuarto del siglo IV a.C. (Talcott y Philippaki 1956: 57, n. 256, pl. 224).

\section{LAS ESCENAS DE APOBATES}

La carrera de apobates era una competición en la que los jóvenes atenienses, armados con la panoplia completa del hoplita o, en ocasiones, solo con yelmo y escudo, montaban y desmontaban una cuadriga al galope controlada por un auriga (los es- 
tudios recientes sobre el tema son los de Reed 1990, Shear 2001, Schultz 2007 y Neils y Schultz 2012). Formaba parte de las Grandes Panateneas y estaba restringida a Atenas y a los ciudadanos atenienses, aunque posteriormente parece haberse celebrado una competición similar en Beocia. Es posible que su introducción en el programa del festival tuviera lugar en el marco de la reorganización del mismo por parte de Pisístrato, es decir, en 566/5 a.C. En el plano mítico, su introducción se debe a Erecteo, el legendario primer rey de Atenas (Apolodoro, Biblioteca 3, 14.6; Higino, Astronomica 2.13) pero su invención se atribuye también a Atenea, quien podría estar representada como prototipo apobático en un número de vasos del siglo vi a.C. (Schultz 2007: 6066). En el siglo IV a.C. la competición estaba en su esplendor y era considerada uno de los mejores y más respetados eventos de Atenas (Demóstenes, Erótico 23-29). Mientras que la competición en sí tendría un origen arcaico, en particular en lo que concierne a su invención por parte de Atenea y Erictonio, su pedigrí es ciertamente homérico. Es un tipo de competición que no refleja prácticas bélicas contemporáneas sino que está enraizada en el mundo homérico, en que los héroes se dirigían a la batalla en carro.

En cuanto a la carrera en sí , los investigadores coinciden en la idea de que los apobates iban montados en cuadrigas al galope conducidas por un auriga o parabates y que cada cierta distancia, debían desmontar y correr junto al carro para volver a montar a continuación. Además, según los testimonios iconográficos del siglo $\mathrm{v}$, es muy probable que la llegada a la meta consistiera en un sprint a pie (Schultz 2007: 63). El momento más peligroso de la carrera era el del desmonte, en el que el apobates se debía agarrar al pasamanos del carro con la mano libre, doblar la rodilla derecha y extender la pierna izquierda hasta casi tocar el suelo, para inmediatamente saltar del carro de espaldas. Tras correr una distancia determinada detrás del carro, debía remontar, lo que solo le requeriría un breve salto hacia delante.

\subsection{ICONOGRAFÍA}

Los primeros testimonios iconográficos claros del tema se encuentran a finales del siglo vi a.C. Una conocida enócoe hoy en Copenhague representa a Atenea como apobates arquetípico, corriendo a gran

\footnotetext{
${ }^{7}$ Además de Demóstenes para el siglo IV a.C., las fuentes literarias relevantes sobre el tema son: Dioniso de Halicarnaso, Antigüedades romanas 7, 73.2-3 y Pseudo-Eratóstenes, Cataterismos 13 (que cita una obra perdida de Eurípides).
}

velocidad hacia la meta, que se marca mediante la terma blanca representada a la derecha de la imagen (Copenhague, Museo Nacional VIII.340). La pose que adopta la diosa en este vaso se repetirá constantemente a partir de ese momento como signo del apobates victorioso: corre hacia la derecha y gira su cabeza hacia atrás, hacia la izquierda, para mirar por encima de su hombro a su oponente invisible.

En el siglo V son los lécitos del grupo de Haimon los que repiten el motivo en más de sesenta ocasiones (sobre estos lécitos, véase Schultz 2007). La iconografía es repetitiva: el carro con el auriga avanza hacia la derecha mientras que el apobates ganador (mirada hacia atrás) corre en un loco sprint hacia la meta. No se representa el momento del desmonte en sí, sino el del último esfuerzo antes de la victoria.

No contamos con testimonios claros sobre representaciones de este tema en la pintura contemporánea. No obstante, Plinio refiere una tabula pintada por Polignoto de Tasos que se encontraba en el pórtico del teatro de Pompeyo en Roma sobre la que comenta que no se sabe muy bien si el hombre con escudo está representado en el momento de ascender o descender (Plin. 35, 9). Carl Robert probablemente acierta cuando interpreta esta tabla como un anatema de un apobates (1895a: 67-68). Así mismo, en 1837 apareció en Herculano un relieve en mármol policromado con una escena de apobates que podría estar copiando un original de Zeuxis o de su grupo, según los análisis estilísticos publicados igualmente por Robert (1895b: 11-20).

En cuanto a la escultura monumental, el tema aparece prominentemente representado en el friso del Partenón, en los lados norte y sur. En el friso norte aparecen 11 grupos de carros y apobates que ocupan 18 de los 47 bloques del friso (XI-XXVIII) (Fig. 7) mientras que en el sur, se representan 10 carros

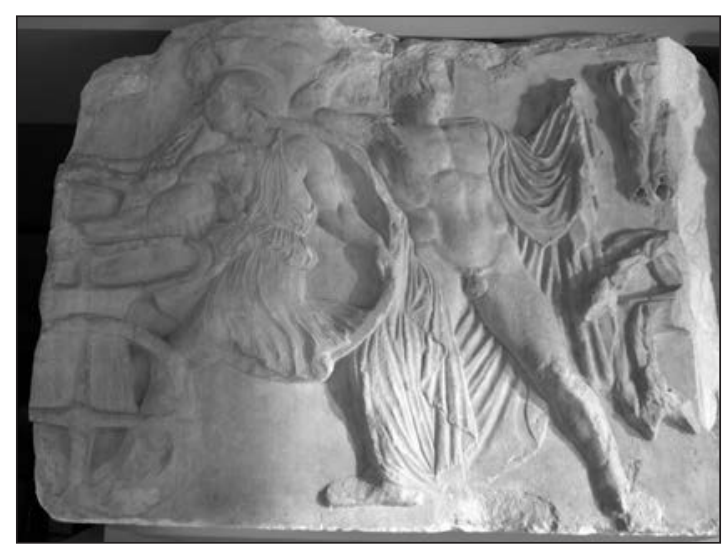

Figura 7. Friso del Partenón con la representación de un carro con auriga y apobates. Fotografía: Diana Rodríguez. 
sobre 10 bloques (XXV-XXXV). En el friso sur las cuadrigas corren hacia la derecha y en el norte, hacia la izquierda. Los apobates aparecen aquí, en su mayoría, en posición oblicua, en el momento del descenso del carro, mientras que el apobates de los bloques XI-XII se diferencia del resto. Según las últimas interpretaciones, es muy posible que este apobates, vestido con un yelmo ático con largas plumas, coraza de cuero, posiblemente un gorgoneo en el pecho y sobre, todo, en la postura habitual del ganador en la tradición iconográfica anterior (corriendo y mirando hacia atrás), sea de hecho el apobates victorioso, representado a punto de ser coronado por el juez (Neils y Schultz 2012).

\subsubsection{La dirección de la cuadriga}

En nuestra opinión, la configuración iconográfica del tema en el friso del Partenón podría explicar algunos de los cambios iconográficos importantes que tienen lugar en la representación de la carrera de apobates en los vasos y en la escultura griegas en torno al año 430 a.C. A partir de este momento, la dirección de la cuadriga del apobates, que en todas las representaciones anteriores avanzaba hacia la derecha, comienza a hacerlo hacia la izquierda, precisamente la dirección que adoptan los carros en el friso norte del Partenón, el que gozaba de una mayor visibilidad en la época.

El último ejemplo de la vieja iconografía se encuentra en una cratera de cáliz del Museo Nacional de Tarquinia (AP6), en la que se representa el apobates montado, armado con yelmo y escudo y vestido con chitón, acompañado del parabates que dirige la cuadriga y Atenea estante detrás de los caballos, en el centro de la composición. En cambio, el que se puede considerar el primer ejemplo de la nueva iconografía, una pélice fragmentaria de Olinto (AP7) datada sobre el año 425 a.C. (es decir, después de la finalización del friso del Partenón), presenta la cuadriga avanzando hacia la izquierda y el apobates adopta allí la característica posición del desmonte consagrada en el friso y sobre la que volveremos luego: se reclina hacia atrás (imaginamos que agarrado al parapeto) mientras posa su pie izquierdo en el suelo. Generalmente la pierna izquierda se representa estirada y es visible detrás de la rueda aunque en este caso la representación es complicada y el apobates, en realidad, ha metido la pierna jentre los radios de la misma! No se conservan restos del auriga. Esta iconografía se repetirá en la mayor parte de los ejemplos de escenas de apobates conservados a partir de ahora, tanto en cerámica como en escultura.

\subsubsection{Nice como auriga}

Otro cambio reseñable que tiene lugar a partir del año 430 a.C. es la introducción de Nice como auriga, puesto que anteriormente desempeñaba un personaje anónimo (sobre la figura de Nice en general, Kefalidou 1996, Rodríguez López 2013). Schultz alude a este detalle e intenta dar una explicación para el mismo ligado a la reinterpretación del frontón oeste del Partenón. Retoma el autor una antigua teoría de E. Petersen según la cual este frontón - en el que aparece la competición de Atenea y Posidón por la ciudad - podría estar relacionado con la carrera de apobates. Sobre la naturaleza de la competición entre las dos divinidades la bibliografía es extensa pero parece plausible que ambos dioses, armados, habrían corrido hasta la Acrópolis, saltado de sus carros y terminado la carrera a pie para finalmente plantar sus armas para reivindicar la victoria. Esta idea arroja luz sobre una serie de problemáticas que presenta este frontón y, en opinión del investigador (Schultz 2007, con bibliografía), también permitiría explicar el motivo por el que, a finales del siglo v a.C., Nice se convierte en auriga en las escenas de apobates, es decir, se debería a una influencia directa del programa escultórico de este edificio. En el frontón oeste del Partenón es Nice quien conduce el carro de Atenea, mientras que Anfítrite se encarga del de Posidón. Una cratera aparecida en Olinto (AP8) (Fig. 8) y que porta una representación de apobates (quizá Atenea) con la diosa de la victoria como auriga es importante en su argumentación. Robinson considera que el motivo de Nice erigiendo un trofeo que se figura en la cara B de esta pieza se tomó directamente del parapeto del templo de Nice en la acrópolis ateniense (1933: 97-99); por su parte, Schultz argumenta que la cara A podría referirse al frontón del Partenón y haber impulsado la noción de Nice como auriga en la carrera de apobates en la pintura de vasos (2007: 67-68).

$\mathrm{Si}$ bien este argumento es plausible, no es plenamente satisfactorio. Incluso si se acepta que la carrera que emprendieron los dioses hacia la Acrópolis siguió el patrón de la carrera de apobates, el frontón oeste no ofrece un modelo iconográfico directo para las representaciones que estamos manejando, es decir, no se representa una carrera de apobates per se. En el único lugar del Partenón donde aparece explícitamente una carrera de apobates que pudiera conformar un modelo iconográfico claro y susceptible de ser imitado es el friso, como ya hemos visto, donde no aparece Nice como auriga en ningún momento. También es destacado el hecho de que la diosa de la victoria solo se incluye en las escenas de apobates en la pintura de vasos, pero no en los relieves del mismo tema. 


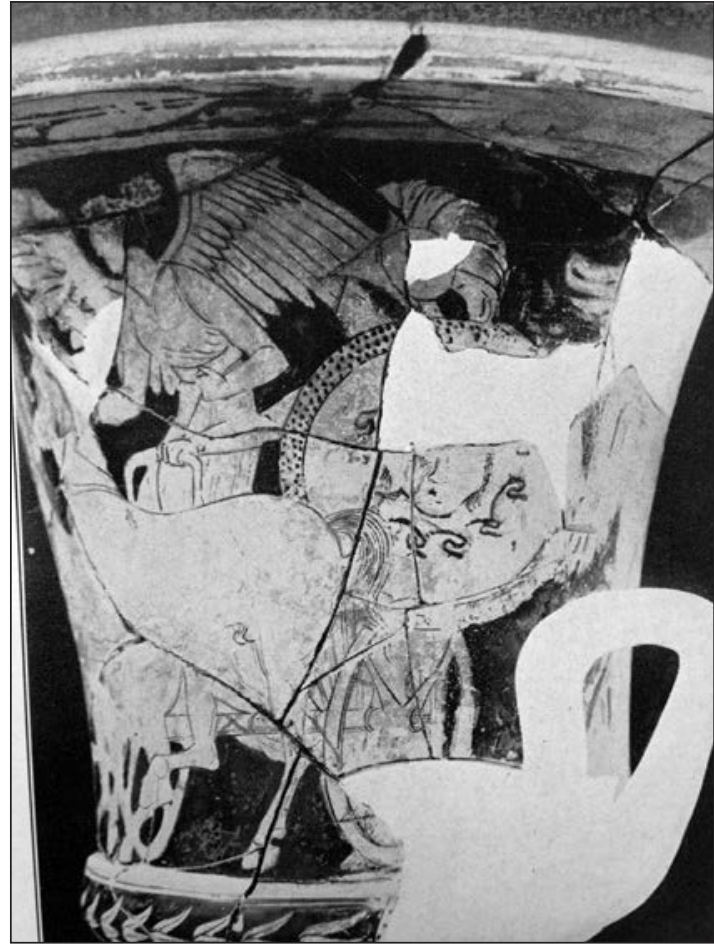

Figura 8. Cratera de cáliz de figuras rojas con una representación de apobates. Tesalónica, Museo Arqueológico. Fotografía: Robinson 1933: 96-99, n.112, fig.117.

Existen cuatro relieves de apobates (AP2-5) (Fig. 9) con una cronología de finales del siglo V-IV a.C. que han aparecido en Atenas y en Oropos (Beocia). Algunos de ellos formaban parte de un monumento erigido con motivo de una victoria en esta carrera. En ninguno aparece Nice como auriga. Cabría pensar que si la introducción de la diosa de la victoria fuera una consecuencia de la asimilación de la iconografía del Partenón, esta no se restringiera a un medio artístico concreto y que se figurara también en los mencionados relieves. Bien es cierto, no obstante, que la tradición de la imagen pública es más difícil de romper por lo que habría que tomar nuestro argumento con cautela ${ }^{8}$. Sin embargo, creemos que la aparición de Nice en los vasos se explica mejor a la luz del lenguaje visual de este medio y los modelos directos que manejaban los pintores que por una hipotética influencia del Partenón. Por ello, consideramos que esta situación apunta más a una asimilación de distintos

\footnotetext{
${ }^{8}$ De hecho, Carpenter (1997: 85) mostró cómo el Dioniso imberbe del Partenón fue rápidamente asimilado por los pintores de vasos mientras que en la escultura pública, la asimilación no fue tan rápida y ambos tipos coexistieron hasta época romana. Agradecemos este dato a la profesora Carmen Sánchez.
}

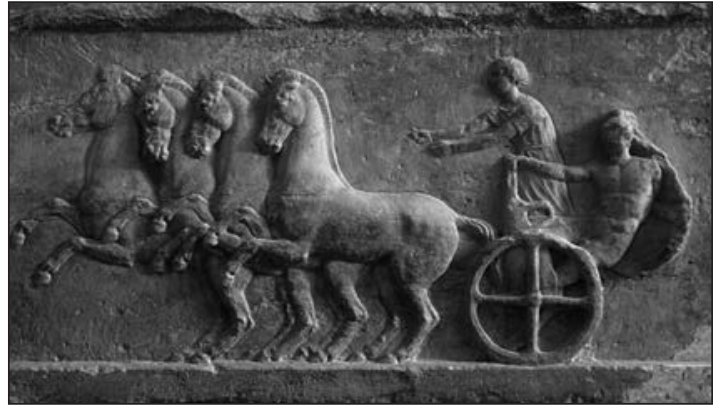

Figura 9. Relieve de apobates. Atenas, Museo de la Acrópolis 1326. Fotografía: (C) Museo de la Acrópolis, Atenas.

elementos iconográficos característicos de dos tipos iconográficos cercanos pero distintos: la apoteosis de Heracles y las escenas de apobates. Analicemos, pues, la naturaleza de esta relación iconográfica.

2.2. EsCENAS DE APOBATES (MEDIADOS DEL SIGLO V Y IV A.C., VASOS Áticos Y ESCULTURA) ${ }^{9}$

Escultura

1. Atenas, Partenón. Friso norte, bloques XI-XXIX y sur, bloques XXV-XXXV.

2. Atenas, Ágora S399. Base con relieve. Mármol del Pentélico. Podría haber formado parte de una bancada o una balaustrada erigida en conmemoración de una victoria en la carrera de apobates. Se reutilizó en la torre norte tardorromana, al sur de la estoa de Atalo. Inscripción SEG XXI 695. Principios del siglo IV a.C.

3. Atenas, Museo de la Acrópolis 1326. Base con relieve. Mármol del Pentélico. Dedicatoria perdida. De la Acrópolis. Siglo IV a.C.

4. Atenas, Museo Arqueológico Nacional 1391. Fragmento de relieve. Inscripción en el geison. Mármol. Del Anfiareo de Oropos, Beocia. Finales del siglo v a.C.

5. Berlín, Pergamonmuseum SK 725. Del Anfiareo de Oropos, Beocia. Principios del siglo IV a.C.

Pintura de vasos

6. Tarquinia, Museo Nacional Tarquiniense RC4195. Cratera de cáliz de figuras rojas. 450 a.C. BADN 14105.

\footnotetext{
${ }^{9}$ Para las obras anteriores, en particular los lécitos del grupo de Haimon, véase la lista elaborada por Schultz 2007: 70-72.
} 
7. Tesalónica, Museo Arqueológico. Pélice de figuras rojas. Sobre 425 a.C. (Robinson 1933: 94, n.107, pl.166).

8. Tesalónica, Museo Arqueológico. Cratera de cáliz de figuras rojas. Sobre 400 a.C. (Robinson 1933: 96-99, n.112, fig.117, pls.168-170).

9. Ágora P19464. Fragmento de cratera de figuras rojas. 390 a.C. (Moore 1997: n.765, pl.779).

10. Oxford, Ashmolean Museum (sin inventario). Fragmento de cratera de campana de figuras rojas. Pintor de Londres F64. De Al Mina, Siria. Primer cuarto del siglo Iv a.C. BADN 275559.

11. Viena, Kunsthistorisches Museum 1049. Cratera de campana de figuras rojas. Pintor de Upsala. 375 a.C. BADN 218066.

12. Heidelberg, Antikenmuseum und Abguss-Sammlung 242. Fragmento, ánfora panatenaica. Sobre 375 a.C.

13. Malibú, Museo J. Paul Getty 79.AE.147. Ánfora panatenaica. 340/339 a.C. Pintor de Marsias.

14. París, Museo del Louvre G527 (Colección Durand). Cratera de campana de figuras rojas. Segundo cuarto del siglo IV. BADN 14061. (Metzger 1951: P1.48.41(A)).

15. Palermo, Museo Arqueológico Regional 2558. Cratera de columnas. De Agrigento. Siglo v a.C. BADN 216077.

16. Palermo, Museo Arqueológico Regional 7. (Shear 2001: 304, nota 336).

\section{RELACIONES ICONOGRÁFICAS ENTRE LAS ESCENAS DE APOBATES Y LA APOTEOSIS DE HERACLES. ANÁLISIS ESTRUCTURAL.}

Hemos apuntado ya en las líneas anteriores ciertos detalles iconográficos que hacen pensar en una relación muy estrecha entre ambas iconografías y que ponen de relieve la existencia de un flujo de influencias entre ellas. Creemos que un análisis estructuralista de ambos motivos iconográficos puede arrojar luz sobre este tema. Por ello, nos vamos a centrar brevemente en los elementos que constituyen la micro-estructura narrativa de ambos temas, el nivel más básico y elemental de la narración pictórica ${ }^{10}$, con objeto de visualizar las diferencias estructurales de ambos motivos así como sus puntos de confluencia. Para ello son útiles toda una serie de metodologías derivadas de la teoría literaria que se han incorporado en las últimas décadas al estudio

\footnotetext{
${ }^{10}$ El término "micro-estructura" es de Stansbury-O'Donnel 1999, cuyo marco metodológico, derivado del análisis estructural de Barthes, seguimos en estas líneas.
}

de las imágenes, en particular el estructuralismo y la semiótica ${ }^{11}$. Al aplicar estas teorías a las imágenes se acepta implícitamente que ambos medios, literatura y artes visuales, se expresan de modo similar, es decir, que ambos forman un lenguaje que es posible leer y descifrar. Así, al igual que un poema se compone de sonidos, letras, palabras, etc., que crean un significado coherente, de igual modo la imagen se sirve de un lenguaje particular, de unos elementos que funcionan de manera semejante a los verbos, al sujeto, a los adverbios, etc. El modelo estructuralista es especialmente útil para analizar la narración en su nivel más básico, como en el caso que nos ocupa, pues permite comprender la mecánica de la estructura narrativa, la sintaxis, identificando las unidades básicas de significado y analizando cómo interactúan a distintos niveles para crear significado ${ }^{12}$ (StansburyO’Donnell 1999: 13).

El estructuralismo define una serie de elementos en el discurso narrativo que se pueden traducir más o menos fácilmente en diferentes componentes de la imagen narrativa: núcleo, catálisis, informantes e índices (Stansbury-O’Donnell 1999: 18-53). El núcleo se define como una acción con final abierto de la que depende la narrativa, se caracteriza por la presencia de un agente, una persona o cosa que actúa; es la base de la narración. Las catálisis son acciones de relleno que magnifican el ámbito de la acción y ofrecen la posibilidad de referirse a otros núcleos que no están representados, tienen por función incrementar la densidad de la narración. Los informantes de la teoría literaria se corresponden con los atributos de los personajes, aquellos elementos de la imagen que también sirven para diferenciar las figuras, tanto por tipo (dioses, esclavos, etc.) como por nombre propio (Heracles, Dioniso, etc.). Los índices, finalmente, se refieren a un acontecimiento, idea o persona fuera de la narración inmediata. En numerosas ocasiones estas categorías se solapan y una única forma dentro de una imagen puede servir múltiples funciones de manera simultánea. La definición de estos elementos en la imagen es importante porque permite visualizar

\footnotetext{
${ }^{11}$ Un estudio y actualización reciente de las diversas metodologías utilizadas para analizar el arte griego puede encontrarse en Stansbury-O'Donnell 2011. Para el uso de estos métodos en la teoría literaria, véase Eagleton 2000.

${ }^{12}$ No obstante si bien estas metodologías son bastante útiles en el nivel que hemos definido, son bastante limitadas para el estudio de la macro-estructura narrativa, es decir, del significado global de la escena, pues su inmovilismo las hace casi inútiles en el marco del modelo interpretativo actual, en el que prima el enfoque postestructuralista y en el que el que entran en juego múltiples conceptos a la hora de interpretar la cultura material de la Antigüedad, tales como el contexto, la agencia, las múltiples relaciones que se establecen entre el artista, el objeto y el espectador, etc.
} 
la narración y abordar estos elementos en cuanto a su función o funciones dentro de la narración.

En el caso de las crateras tempranas con la apoteosis de Heracles con composición en dos registros, la escena se estructura en torno a dos núcleos narrativos: Heracles en la cuadriga y mujeres o sátiros apagando la pira funeraria, si bien este último núcleo más bien podría interpretarse como una catálisis. Diversas figuras y elementos iconográficos funcionan en estas escenas como índices e informantes, identificando la escena y los personajes y apuntando ideas extra narrativas. En las versiones posteriores, el pintor prescinde de elementos secundarios de la narración para concentrarse solo en el núcleo principal de la acción: la cuadriga portando una figura masculina y una femenina. La clava funciona como informante esencial para la identificación de la figura como Heracles al igual que las alas para el reconocimiento de Nice y el escudo en el caso del apobates.

Ambos temas, en la configuración que estamos analizando surgen casi de manera contemporánea en la pintura de vasos por lo que es difícil proponer la preeminencia de uno sobre otro. Los núcleos de ambas narraciones se estructuran de la misma forma: hombre + carro + auriga, con una serie de informantes y catálisis característicos que precisan el sentido en cada uno de ellos: clava, Hermes y Nice en el caso de Heracles; panoplia, posición oblicua, terma, ausencia de Hermes, para la carrera de apobates. En las piezas más sencillas, la distinción tiene lugar exclusivamente en base a la presencia de clava o de panoplia, pues el resto de signos iconográficos son comunes. Las similitudes entre ambas iconografías a nivel estructural son pues evidentes y es posible que se traduzcan también al plano del significado, como se explicará luego. Es más, un análisis detallado de las dos iconografías releva un interesante trasvase de informantes y catálisis entre ambas. Diversos signos iconográficos fluctúan entre ambos núcleos y proporcionan un material muy importante a la hora de investigar la posible asimilación de la apoteosis de Heracles y del apobates victorioso en el plano significativo. Identifiquemos, pues, esos "intrusos".

\subsection{Gestos y Personajes fuera de LUgar: Nice, HERMES Y EL GESTO DEL DESMONTE}

Más arriba referimos ya la problemática en torno al personaje de Nice, que se introduce en las escenas de apobates en la cerámica alrededor del 430 a.C. A partir de este momento, estará presente en casi todos los vasos que representan el tema pero no aparecerá nunca en los relieves escultóricos. Nice, al mismo tiempo, se figura en gran parte de las escenas de la apoteosis de Heracles a partir de finales del siglo $\mathrm{v}$ a.C. Su introducción en las escenas de apobates, en este caso, creemos que tiene más que ver, como explicamos más arriba, con los tipos iconográficos que manejaban los pintores de vasos, y en particular con el de la apoteosis de Heracles, que con una influencia iconográfica directa del frontón del Partenón. No obstante, tampoco se debe exagerar la influencia del tema heracleo en este caso ni considerar a Nice una intrusa en las escenas de apobates cuya presencia se justificaría por una influencia directa del tema de la apoteosis. Más que intrusa, consideramos que es una introducción conveniente para ambos temas, pues aporta resonancias significativas distintas a las generadas por Atenea y que están muy en línea con el espíritu de la "iconografía nueva" del siglo IV a.C. De hecho, Nice no es un elemento indispensable en el tema de Heracles. Es un simple índice, no es parte indispensable del núcleo y su presencia o ausencia no altera la acción de este en absoluto. Es más, la presencia de la clava es más necesaria para la identificación del tema que la de la diosa alada. Sin embargo, en su papel de índice sí introduce matices significativos a los que aludiremos más adelante.

De manera interesante, las fuentes literarias sobre la apoteosis del héroe no refieren la subida de Heracles al Olimpo en cuadriga y por ende, la introducción de la diosa en el papel de auriga es una adición iconográfica que se debe a los propios pintores de vasos y que encuentra su fundamento en la creciente importancia que va otorgándose a esta figura en la Atenas del siglo V (baste recordar el templo de Atenea Nice, cuya construcción comenzó alrededor del año 420 a.C.). Nice será una presencia cada vez más importante en la pintura de vasos a partir de esta época y adoptará un papel muy significativo en la obra de algunos pintores del siglo IV a.C., como el Pintor de Toya. Es esta diosa, por lo tanto, el personaje más idóneo para dirigir una cuadriga victoriosa, sea la de Heracles en su camino al Olimpo, es decir a su inmortalidad, o la del joven que vence en la competición más estimada de las Panateneas. Ambas son escenas de triunfo. La sustitución de Atenea — presente tanto en las versiones arcaicas como en la pélice de Munich- por Nice en la apoteosis del héroe habría que entenderla en este contexto. Un momento iconográfico intermedio es una ánfora campana del Pintor de Talos en que la Victoria no conduce el carro pero se figura en dos ocasiones bajo las asas, en una de ellas, sostiene la corona de laurel para ceñir al héroe (quien, por otra parte, aparece ya coronado) y en la segunda, porta un timiaterio y una fiala para realizar la libación en su honor. 
En cuanto al gesto del desmonte, este lo hemos definido como la posición oblicua que adopta el apobates en el carro, con la rodilla derecha semiflexionada y la izquierda extendida detrás de la rueda a punto de tocar el suelo, preludio del salto hacia atrás (Fig. 3 y 9). Este gesto tan característico aparece por primera vez en el friso del Partenón e inmediatamente se incorpora en la pintura de vasos, aunque de un modo menos exagerado que en los relieves de finales del siglo V-IV a.C., en particular cuando el espacio vacío a la derecha de la cuadriga es suficiente para permitir tal posición. De manera interesante este gesto se cuela también en las escenas de la apoteosis de Heracles a partir del año 400 a.C. (Fig. 10). Es especialmente obvio en el ánfora del Pintor de Talos y también está presente en el fragmento de Los Nietos motivo de este estudio (Figs. 1 y 2).

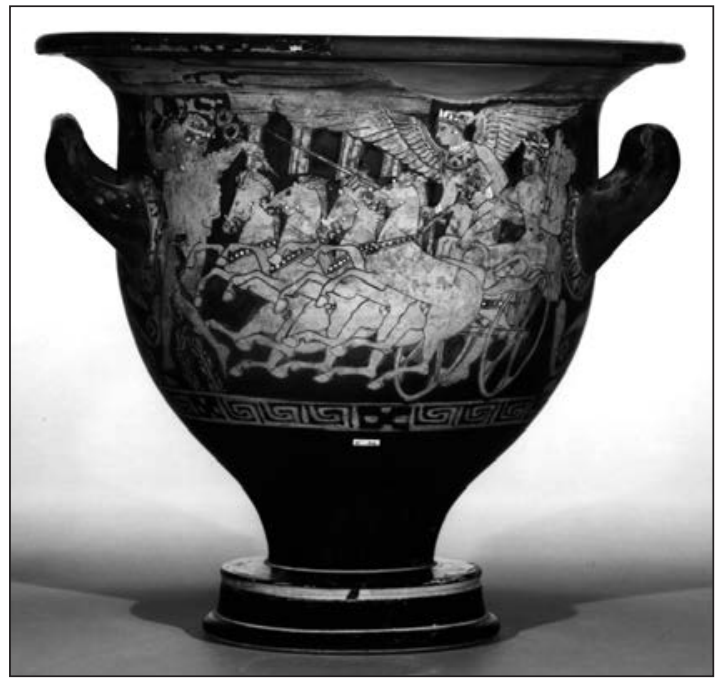

Figura 10. Cratera de cáliz de figuras rojas con la representación de la apoteosis de Heracles. Londres, British Museum F64. Fotografía: (C) Trustees of the British Museum.

Finalmente, una prueba más de las relaciones de ambos temas es la presencia de un "intruso" muy particular en las escenas de apobates. Se trata de Hermes, que hace su aparición en una cratera de campana del Pintor de Upsala con el tema del apobates (AP11) (Fig.11). Este pinta escenas de apoteosis en dos ocasiones: en la cratera de la colección Mynors (H9), Heracles monta la cuadriga que conduce Nice mientras Apolo, identificado por la eirisione, avanza hacia el carro. Una pequeña Nice vuela sobre el primer caballo. En el campo de la imagen cuelgan ramas de laurel y debajo de la cuadriga se representa el mundo marino: tres peces y un delfín indican el vuelo del carro. Una escena similar pinta en una cra- tera de Bologna (H8). Repite el laurel, los peces y la cuadriga con Heracles e introduce delante del caballo la figura habitual en estas escenas, Hermes en lugar de Apolo, corriendo y con el caduceo bien visible en la mano derecha. El aspecto interesante de estas producciones tiene que ver con la introducción de Hermes -identificado por la clámide y el caduceo en la tercera cratera que pinta (AP11) (Fig. 11), la de la carrera de apobates, contexto en el que el dios está completamente fuera de lugar ${ }^{13}$. Este "desliz" es un testimonio de gran importancia que prueba, a nuestro juicio, la estrecha relación de ambas iconografías en la mente de los pintores de vasos.

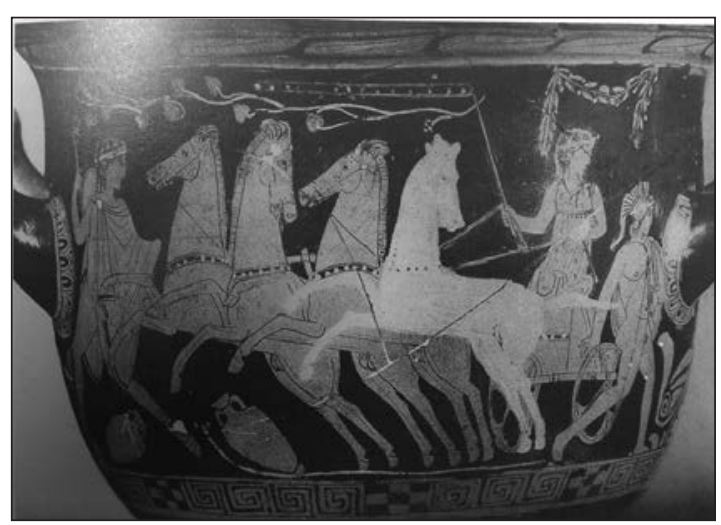

Figura 11. Cratera de campana de figuras rojas con la representación de una escena de apobates. Viena, Kunsthistorisches Museum 1049. Fotografía: Tiverios 1991: 21, Fig. 25.

\section{APOTEOSIS DE HERACLES/APOBATES VIC- TORIOSO EN CONTEXTO IBÉRICO: ¿UN MIS- MO SIGNIFICADO?}

Después de los análisis presentados cabe preguntarnos si la relación entre ambos temas se reduce al plano "sintáctico" o se traduce también en una asimilación conceptual. Es decir, ¿significa lo mismo la apoteosis de Heracles que el triunfo del apobates?

Creemos que sí. En realidad, el mensaje que transmiten ambos es ciertamente similar: visualizan una promesa de inmortalidad, en el caso de Heracles, materializada en su introducción en el Olimpo como un dios tras una vida de esfuerzos sobrehumanos y en el caso del apobates, a través de la fama "olímpica", de la victoria en una de las carreras más complicadas de las Grandes Panateneas, que requería el dominio

\footnotetext{
${ }^{13}$ Otra ocasión en la que Hermes se representa en posición similar delante de un carro es el relieve de Echelos, hallado en Falero. Atenas, Museo Arqueológico Nacional 1783. Finales del siglo V a.C. (Vermeule 1955: 108).
} 
de muy diversas técnicas. El hecho de que ambos núcleos narrativos se estructuren de la misma manera, las relaciones entre ellos y la fuga de elementos iconográficos característicos que hemos puesto en evidencia son significativos. Es importante considerar también el modo en que el espectador antiguo se enfrentaba a su cultura visual, proceso que puede ser reconstruido a grandes rasgos a través de descripciones antiguas de obras de arte (sobre este aspecto, véase Stansbury-O'Donnell 1999: 55-70). Los últimos estudios al respecto coinciden en que el primer paso del proceso de visualización consistía en la identificación rápida del tema de la imagen narrativa, es decir, la identificación del núcleo, de la acción, para después proceder a refinar esa información adquirida en un primer instante mediante la asimilación del resto de elementos de la composición, como los informantes que, como bien expresa Stansbury O'Donnell (1999: 92), identifican a las figuras más que al tema. En este proceso, la manera de estructurar el núcleo adquiere pues, una importancia capital, se dirige directamente a nuestra mente activando los mecanismos de reconocimiento de la imagen. Al mismo tiempo, enraizados en un contexto cultural preciso, determinados núcleos se van cargando de significaciones que trascienden la mera acción representada y adquieren un valor de índice, de hieroglifo, compartido por el productor de la imagen y su público receptor. En este caso, el personaje que avanza en un carro conducido por Nice sirve también como índice paradigmático que alude a la recompensa posterior a la muerte, y las relaciones entre ambas escenas indican que el viaje en cuadriga va a convertirse en una narración casi genérica en referencia al viaje a un más allá que comienza a concebirse de una manera mucho más amable en esta época.

Otro detalle iconográfico que hemos comentado con anterioridad apunta también en este sentido. Se trata de la dirección de la cuadriga. Hemos visto que en los últimos decenios del siglo v a.C. el carro del apobates cambia de dirección y comienza a mirar a la izquierda, al igual que el del héroe. Quizá este cambio se deba a la influencia del Partenón pero en el plano significativo adquiere relevancia en relación con la cuadriga de Heracles. La dirección de avance de las figuras en el arte griego es importante y cumple una función narrativa esencial ${ }^{14}$. La derecha connota la fuerza heroica, la victoria, la superación. Es la dirección en la que parten los héroes - conocidos

${ }^{14}$ Un estudio básico al respecto y asombrosamente poco citado en la bibliografía es el de Heinz Luschey 2002. La investigación fue parte de su trabajo de habilitación universitaria durante de los años cincuenta y se publicó de manera póstuma en 2002 . o anónimos - y también los dioses a la batalla, es la dirección del vencedor en el duelo fatal. Este se coloca a la izquierda, el vencido, a la derecha. Es también la dirección del tiasos, de los que se alejan y de los que dejan el hogar por la guerra. En cambio, el movimiento hacia la izquierda es el de la vuelta a casa, el camino desde el campo de batalla, el del retorno del héroe, y también es la dirección que toma Heracles en su introducción en el Olimpo, tanto a pie, como en carro (Luschey 2002: 30). Es la dirección que adopta ahora también la cuadriga del apobates, que antes corría hacia la derecha, tal y como corresponde a un carro vencedor. Si el significado de las escenas de triunfo deportivo siempre han sido proclives a la interpretación en clave funeraria, la asimilación de ambas iconografías potenciará aún más estas resonancias en las escenas de apobates.

Este cambio hacia una mayor indeterminación temática, hacia escenas con un contenido más simbólico que puramente narrativo, que aluden a ambientes más que narran acciones, es una de las características más destacadas de la iconografía del siglo IV a.C. (véase al respecto, Metzger 1951) y permite así mismo una mayor adaptabilidad significativa de las imágenes atenienses a contextos culturales extra helénicos, que son, durante el siglo IV a.C. los receptores habituales de muchas de estas producciones, en particular, el Mediterráneo occidental, Iberia principalmente en el siglo IV a.C., y las zonas del Ponto.

En este contexto deben entenderse también, a nuestro juicio, un pequeño número de imágenes en las que Nice aparece como única ocupante de una cuadriga que avanza hacia la izquierda, como en una cratera de campana de Toya (MAN 1986/149/206). La referencia al evento en concreto ya no importa, ya no hay apobates ni Heracles, Nice conduce el carro en solitario como imagen de la victoria sobre la muerte. Como acompañante de la diosa ya solo queda el alma del difunto que, tanto en contextos suditálicos ${ }^{15}$ como ibéricos, se enterraba en/con estas crateras.

Este tipo de imágenes eran muy queridas por los iberos porque su indeterminación propiciaba la interpretatio ibérica en clave funeraria, tema ampliamente explorado (Olmos 1990; Sánchez Fernández 1992, 1997). El poco probable conocimiento de la carrera ateniense en la Península Ibérica refuerza la idea de que la imagen del apobates en este contexto se entendería de manera genérica como alusión al viaje funerario. Las imágenes de Nice, por otro lado,

\footnotetext{
${ }^{15}$ Véase por ejemplo la cratera de campana suditálica número 32657 del Museo Arqueológico Nacional y el comentario sobre la misma en el catálogo online del museo. Sobre el viaje funerario en el mundo suditálico, véase Cabrera Bonet 1997.
} 
son muy abundantes entre las piezas exportadas a estos territorios de occidente. Un caso interesante lo encontramos en la cratera de Toya del Pintor de Toya en la que la diosa corona al vencedor en otro evento deportivo, una lampadedromia en este caso (MAN 1986/149/205).

No sabemos qué destino podría haber tomado la cratera origen de este estudio tras su paso por el almacén de Los Nietos. Quizá si, tal y como suponen sus excavadores, este complejo funcionaba como centro redistribuidor de cerámica en el área sureste de la Península (García Cano y García Cano 1992), esta cratera habría seguido el mismo camino que otras de la zona y habría encontrado descanso eterno en la tumba de algún ibérico destacado.

¿Apoteosis de Heracles o escena de apobates? Poco importan ya los debates iconográficos en el espacio liminar de la tumba; allí, ya solo queda esperar que se realice la promesa que encierran ambas imágenes: la del viaje triunfal al allende.

\section{BIBLIOGRAFÍA}

Boardman, J. 1972: "Herakles, Peisistratos and Sons", Revue archéologique 1, 57-72.

Boardman, J. 1975: "Herakles, Peisistratos and Eleusis", The Journal of Hellenic Studies 95, 1-12.

Boardman, J. 1989a: Athenian Red Figure Vases. The Classical Period, London.

Boardman, J. 1989b: "Herakles, Peisistratos and the Unconvinced", The Journal of Hellenic Studies 109, 158-159.

Brinkmann, V., Kaeser, B., Knauss, F., Lorenz, S., Schmölder-Veit, A., Schulze, H. y Wünsche, R. 2003: Herakles. Herkules, München.

Brommer, F. 1944: Satyrspiele: Bilder griechischer Vasen, Berlin.

Cabrera Bonet, P. 1997: "El viaje al allende a través del mar: un 'ascos de Escila' en el M.A.N.", Boletín del Museo Arqueológico Nacional 15, 77-90.

Carpenter, T. 1997: Dionysian Imagery in Fifth-Century Athens, Oxford.

Clairmont, C. 1953: "Studies in Greek Mythology and Vase-Painting", American Journal of Archaeology 57, 85-94.

Cochrane, E. 1991: "The Death of Heracles", Aeon. A Symposium on Myth and Science II, 55-73.

Eagleton, T. 2000: Literary Theory. An Introduction, Oxford.

Faraone, C. 1997: "Salvation and Female Heroics in the Parodos of Aristophanes Lysistrata", The Journal of Hellenic Studies 117, 38-59.
Finkelberg, M. 1996: "The Second Stasimon of the 'Trachiniae' and Heracles Festival on Mount Oeta", Mnemosyne: Bibliotheca Classica Batava 49, 129-143.

Frickenhaus, A. 1911: "Das Herakleion von Melite", Athenische Mitteilungen 36, 113-144.

García Cano, C. y García Cano, J. M. 1992: “Cerámica ática del poblado ibérico de La Loma del Escorial (Los Nietos, Cartagena)", Archivo Español de Arqueología 65, 3-32.

García Cano, J. M. y Gil, F. 2009: La cerámica ática de figuras rojas: talleres y comercio (siglo IV a.C.). El caso de Coimbra del Barranco Ancho (Jumilla, Murcia), Murcia.

Holt, P. 1989: "The End of the Trachiniai and the Fate of Herakles", The Journal of Hellenic Studies 109, 69-80.

Holt, P. 1989: "The End of the Trachiniai and the Fate of Herakles", The Journal of Hellenic Studies 109, 69-80.

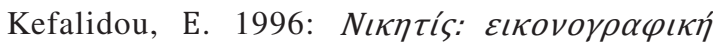

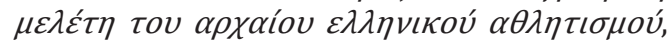
$\Theta \varepsilon \sigma \sigma \alpha \lambda$ оvเкп.

Lissarrague, F. 1990: "Why Satyrs are Good to Represent", J. Winkler y F. Zeitlin (eds.), Nothing to do with Dionysos? Athenian Drama in its Social Context, Princeton, 228-236.

Luschey, H. 2002: Rechts und Links. Untersuchungen über Bewegungsrichtung, Seitenordnung und Höhenordnung als Elemente der Antiken Bildsprache, Tübingen/Berlin.

Mertens, J. 2010: How to Read Greek vases, New York/New Haven/London.

Metzger, H. 1951: Les représentations dans la céramique attique du IVe siècle, Paris.

Mingazzini, P. 1925: Le rappresentationzi vascolari del mito dell'apoteosi di Herakles, Roma.

Mitchell, A. 2009: Greek Vase-Painting and the Origins of Visual Humour, Cambridge.

Moore, M. B. 1997: Attic Red-Figured and WhiteGround Pottery, Princeton.

Neils, J. y Schultz, P. 2012: "Erechtheus and the Apobates Race on the Parthenon Frieze (North XI-XII)", American Journal of Archaeology 116, 195-207.

Nilsson, M. P. 1963: The Mycenaean Origin of Greek Mythology, New York.

Olmos, R. 1990: "Orgiastic Elements in Iberian Iconography?", Kernos 5, 153-171.

Reed, N. 1990: "A Chariot Race for Athens Finest: The Apobates Contest Re-Examined", Journal of Sport History 17, 306-317.

Richter, G. M. A. 1941: "A Greek Silver Phiale in the Metropolitan Museum", American Journal of Archaeology 45, 363-389. 
Robert, C. 1895a: Die Marathonschlacht in der Poikile, Halle.

Robert, C. 1895b: Votivgemälde eines Apobaten, Halle.

Robinson, D. M. 1933: Excavations at Olynthus Part 5. Mosaics, Vases, and Lamps of Olynthus found in 1928 and 1931. Baltimore.

Rodríguez López, I. 2013: "Aproximación a la iconografía de Nike en el arte griego", Eikon/Imago 3, 96-112.

Sánchez Fernández, C. 1992: "Imágenes de Atenas en el mundo ibérico: análisis iconográfico de la cerámica ática del siglo IV a.C. hallada en Andalucía Oriental", Anuario del Departamento de Historia y Teoría del Arte 4, 23-34.

Sánchez Fernández, C. 1997: "Imágenes de la muerte en una tumba ibérica. El ajuar ático de la tumba 43 de Baza (Granada)", Boletín del Museo Arqueológico Nacional 15, 37-48.

Schultz, B. P. 2007: "The Iconography of the Athenian Apobates Race: Origins, Meanings, Transformation", O. Palagia y A. Choremi-Spetsieri (eds.), The Panathenaic Games. Proceedings of an international conference held at the University of Athens (May 11-12, 2004), Oxford, 59-73.

Seidensticker, B. 1989: Satyrspiel, Darmstadt.

Shapiro, H. A. 1983: "Hêrôs Theos"”: The Death and Apotheosis of Herakles", The Classical World 77, 7-18.

Shapiro, H. A. 1990: "Old and New Heroes: Narrative, Composition, and Subject in Attic Black-Figure", Classical Antiquity 9, 114-148.

Shear, J. L. 2001: Polis and Panathenaia: The History and Development of Athena's Festival, Pennsylvania, Tesis doctoral inédita.
Stansbury-O'Donnell, M. 1999: Pictorial Narrative in Ancient Greek Art, Cambridge.

Stansbury-O`Donell, M. 2011: Looking at Greek Art. Cambridge.

Sutton, D. 1974: "A Handlist of Satyr Plays", Harvard Studies in Classical Philology 78, 107-143.

Talcott, L. y Philippaki, B. 1956: "Figured Pottery", Hesperia Supplements 10, 1-223.

Taplin, O. 1993: Comic Angels and other Approaches to Greek Drama through Vase-Paintings, Oxford.

Taplin, O. 2007: Pots \& Plays: Interactions between Tragedy and Greek Vase-Painting of the Fourth Century B.C., Los Angeles.

Taplin, O. y Wyles, R. 2010: The Pronomos Vase and its Context, Oxford.

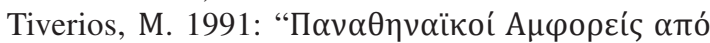

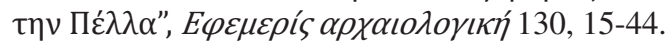

Trendall, A. D. y Webster, T. B. L. 1971: Illustrations of Greek Drama, London.

Vermeule, C. C., III. 1955: "Chariot Groups in FifthCentury Greek Sculpture", The Journal of Hellenic Studies 75, 104-113.

Vollkommer, R. 1988: Herakles in the Art of Classical Greece, Oxford.

VV.AA. 1981-1999: Lexikon Iconographicum Mythologiae Classicae, Zurich/München/Düsseldorf.

Walsh, D. 2009: Distorted Ideals in Greek VasePainting: The World of Mythological Burlesque, New York.

Woodford, S. 1971: "Cults of Heracles in Attica", D. Gordon Mitten, J. Griffiths Pedley y J.A. Scott (eds.), Studies presented to George M. A. Hanfmann, Mainz, 211-225.

Recibido: 26-07-2013

Aceptado: 08-01-2014 